\section{AB1111 ARTHRITIS IS NOT A PREREQUISITE DISEASE MANIFESTATION FOR THE DIAGNOSIS OF SYSTEMIC JIA: RESULTS OF A PROSPECTIVE COHORT TRIAL USING RIL-1RA AS FIRST LINE TREATMENT WITH LONG TERM FOLLOW-UP}

N.M. Ter haar ${ }^{1}$, A. Leek ${ }^{1}$, A. El Idrissi ${ }^{1}$, J.F. Swart ${ }^{1}$, J. van Loosdregt ${ }^{2}$, N. Wulffraat ${ }^{1}$, S. de Roock ${ }^{1}$, S. Vastert'. ${ }^{1}$ Pediatric Rheumatology and Immunology, ${ }^{2}$ Laoratory for Translational Immunology, University Medical Center Utrecht, Utrecht, Netherlands

Background: Systemic onset juvenile idiopathic arthritis (sJIA) is a multifactorial disease, characterised by arthritis, spiking fever, skin rash, lymphadenopathy, hepatosplenomegaly and/or serositis, in combination with increased inflammatory parameters as erythrocyte sedimentation rate (ESR), C-reactive protein (CRP) and ferritin. SJIA is nowadays seen as a complex autoinflammatory disorder. However, in the current ILAR classification, SJIA is still classified under the umbrella of JIA. The past decade has learned that the mechanisms underlying the systemic inflammation in SJIA differ in important aspects from the other subtypes like polyarticular JIA.

Objectives: Here we compare disease characteristics, manifestations and response to treatment of ILAR-criteria fulfilling SJIA $(n=30)$ and 'sJIA without arthritis' $(n=12)$, in order to evaluate whether arthritis should still be a prerequisite for the diagnosis of SJIA.

Methods: We included 30 consecutive diagnosed and prospectively followed new onset sJIA patients as well as 12 'sJIA without arthritis' from our paediatric rheumatology clinic from 2008 until 2017. The 'sJIA without arthritis' patients underwent extensive diagnostic procedures to exlude infections (PCR, blood cultures, serology etc), malignancies (bone marrow punctures, PET scans etc) and other diagnoses.

All patients followed a standardised treatment protocol, starting with rIL-1RA $\left(2 \mathrm{mg} / \mathrm{kg}\right.$ ) as 1st line treatment (without steroids), as previously described(. ${ }^{1}$ In case of partial response, rlL-1RA dose was raised to $4 \mathrm{mg} / \mathrm{kg}$ with a maximum of $200 \mathrm{mg} /$ day. If that failed, corticosteroids were added and/or patients switched to alternative biologicals as canakinumab or tocilizumab. If patients had inactive disease at 3 months after start of rIL-1RA treatment, rIL-1RA was tapered for a month (alternate day regimen) and subsequently stopped.

Peripheral blood samples were taken before initiation of rIL-1RA and at all followups for routine lab measurements. For biomarker analyses, serum was isolated at disease onset and at three months after initiation of rlL-1RA.

Results: There were no differences in disease manifestations like skin rash, serositis, hepatosplenomegaly or symptoms like arthralgic (painful) joint count between SJIA and 'sJIA without arthritis" patients at diagnosis. Nor was there a difference in the levels of CRP, ESR, ferritin or IL-18 at start of therapy.

Importantly, also the response to rIL-1RA treatment did not differ between sJIA and 'sJIA without arthritis' patients in our cohort. At last follow-up (median 5,8 years, IQR $2,9-7,6$ years), $95 \%$ of patients had inactive disease, of which $72 \%$ off medication.

Conclusions: Based upon disease manifestations and inflammatory parameters in patients with confirmed SJIA and 'sJIA without arthritis' at disease onset and on excellent treatment responses to a standardised treatment protocol with rIL-1RA as 1 st line treatment, we conclude that arthritis should not be a prerequisite disease criterium in the next classification criteria of SJIA.

\section{REFERENCE:}

[1] : Vastert, SJ et al, Arthritis Rheumatology 2014. doi: 10.1002/art.38296.

Disclosure of Interest: None declared

DOI: 10.1136/annrheumdis-2018-eular.7392

\section{AB1112 $\quad$ AUTOANTIBODIES IN CHILDREN WITH JUVENILE ARTHRITIS ON BIOLOGICAL THERAPY}

O.A. Oshlyanska. connective tissue disorders in children, State Institute of Pediatrics, Obstetrics and Gynecology, Academy of Medical Sciences of Ukraine, Kyiv, Ukraine

Background: Antinuclear antibodies (ANA) are described as initial serological findings in juvenile idiopathic arthritis (JIA). SLE-like syndromes with ANA seroconversion have been described in the patients on biological therapy, including JIA children. Biologics have been used in Ukraine since 2011. In 459 of 2,542 JIA cases registered in 2016, patients were on biologics. According to the data of the Ukrainian Registry of Patients Receiving Biologics, autoimmune diseases as complications of biological therapy have not been registered in Ukraine so far. Objectives: To study the ANA dynamics in JIA children on biologics.

Methods: There was conducted a retrospective observational study which involved 138 JIA patients, including 44 children with the biologics as follows: TOZ 12, ADA 29, ETA 3. JIA markers (HLA B27 (PCR), RF (ELISA), aCCP (immunosorption), ANA (IFT and ELISA (10 subtypes) were determined in patients at the disease onset and after 1,2,5 years of biologics medication.

Results: Among all JIA patients, ANA were detected in $54 \%$ of oJIA, $47 \%$ of pJIA $7 \%$ of all spondyloarthropathy $(\mathrm{spA})$ cases. At the beginning of biologics, only $22 \%$ children were ANA-positive, $66 \%$ of them being female, mean age at the dis ease debut was $6.9 \pm 3.81 \mathrm{y}$. The median of the time from the disease onset to the initiation of biologics was $4.2 \pm 3.2 \mathrm{y}$. The mean age at biologic therapy start was $10.3 \pm 4.18 \mathrm{y}$. At the time of the examination, the mean duration of biologics was $2.4 \pm 1.46 \mathrm{y}$. In pJIA onset ANA were detected in $62 \%$ of patients, in oJIA with uveitis in $75 \%$, in spA in $14.2 \%$; in SJIA ANA were not identified. RF and aCCP were found in 2 pJIA children; HLA B27 was detected in 1 child with uveitis and in $64.2 \%$ of patients with $\mathrm{spA}$. The data obtained showed that ANA were found more often in patients on biologics than in general JIA population ( $p J \mid A, p=0.04$, oJIA $p=0.02)$, RF was lower $(4.5 \%)(p=0.001)$. The relationship with the sex was not seen $(r=0.19) .21 .4 \%$ of patients had been ANA positive before ADA therapy initiation. Reverse seroconversion was seen in most patients after a year of ADA ther apy (3.5\% remained ANA+, reduced ANA titer). After 2 year medication, ANA were detected by IFT in 3 seronegative at the disease debut patients (7.1\%). They had negative antibodies to histones and aDNAII (ELISA). After 5 y, 2 patients on ADA remained ANA+. Among patients on ADA, who had ANA as a new phenomenon there were 2 female and 1 male teens in disease remission. They had no clinical manifestations of secondary autoimmune pathology. All the patients continued methotrexate, corticosteroids were discontinued in 2 of them. All patients were on isoniazid medication for over a year. In RF +patients on ADA, the RF was not detected a year later, after $2 \mathrm{y}$ it was revealed in $1 \mathrm{pJIA}$ patient who was RF neg (aCCP neg). There was $1 \mathrm{RF}+$ case at pJIA debut with TOZ, after the therapy it was not detected. Two paediatric patients on TOZ (16.6\%) were ANA +at the debut, but the subsequent dynamics studies did not detect ANA (TOZ vs ADA $\mathrm{p}=0.04$ ). Patients treated with ETA were observed for less than 1 year.

Conclusions: ANA types which are detected at JIA debut and after initiation of biologic treatment may differ. It is suggestive of the biologics potential to modify the immune response, thus increasing the risk of overlap-syndromes. Therefore, it is advisable to monitor autoantibody titers in JIA children on biologic treatment.

Disclosure of Interest: None declared

DOI: 10.1136/annrheumdis-2018-eular.3094

\section{\begin{tabular}{|l|l}
\hline AB1113 & PREVALENCE OF GENERALISED JOINT
\end{tabular} HYPERMOBILITY IN THE CHILDREN POPULATION OF ORDU; TURKISH STUDY}

Ö.F. Barçak ${ }^{1^{*}}$, S.S. Dedeoğlu2 ${ }^{1}{ }^{1}$ Physical Medicine and Rehabilitation, Özel Ünye Çakırtepe Hastanesi, Ordu; ${ }^{2}$ Orthopedics and Traumatology, Okmeydanı Training and Research Hospital, İstanbul, Turkey

Background: Generalised Joint hypermobility $(\mathrm{GJH})$ is a clinical conditions that may cause common musculoskeletal pain during childhood. In our study, we aim to show the prevalence of GJH in children of 11-18 age group, and to provide guiding information for rheumatologists and paediatricians who are interested in this subject.

Objectives: Our study aimed to evaluate the frequency of GJH in children aged 11-18 years in the province, Ordu.

Methods: This cross-sectional study was performed with 410 students aged $11-$ 18 years who receive education in the province, Ordu. Questionnaire forms were filled in, and each student was examined. The children, who reported to have any disease, were excluded from the study. GJH was diagnosed according to criteria of Beighton diagnosis.

Results: A total of 410 students, 210 of whom were girls (51.3\%) and 200 $(48.7 \%)$ of whom were boys, participated in the study. The subjects' mean age was $13.7 \pm 1.7$ years for girls and $13.1 \pm 1.79$ years for boys. The body mass index (BMI) of the girls was $21.5 \pm 3.4 \mathrm{~kg} / \mathrm{m}^{2}$ and of the boys were $22 \pm 3.8 \mathrm{~kg} / \mathrm{m}^{2} .160$ $(39 \%)$ of the students participated from the city centre and $250(61 \%)$ from the district centres. The presentations of the students to the health institution due to any complaint in 1 year were examined. The students participating in the study were questioned in terms of presence and time of previous joint complaints. Accord ingly, the number of participants who previously had a joint-related complaint was found to be $155(37.8 \%) .40(10.7 \%)$ of these participants had a joint-related complaint 3 months ago, $18(4.3 \%)$ had it 6 months ago, $40(9.7 \%)$ had it 1 year ago and $47(11.4 \%)$ had it more than one year ago. The frequency of GJH was $8.7 \%$ 24 of 36 participants in whom GJH was detected and had a Beighton score of 5 and above consisted of girls; and this was $11.4 \%$ of the girls. The number of male participants in whom GJH was detected, was found to be 12 ; and this was $6 \%$ of the boys. There was a significant difference between female and male participants in terms of the frequency of GJH ( $p=0.021)$.A statistically significant and highly negative correlation was found between age and Beighton score $(r=-0.182$ $p<0.001$ ). A statistically significant and highly negative correlation was found between body mass index and Beighton score $(r=-0.092, p<0.05)$. 
Conclusions: One of the most common complaints seen during the childhood is musculoskeletal system pain. As shown by various studies performed, one of the significant reasons of extremity pain is $\mathrm{GJH} .{ }^{1}$ In our study, no significant correlation was found between GJH and joint pain. GJH is a disease that may cause musculoskeletal system pain during childhood. In our study which investigates the frequency of GJH in our region, we detected the GJH prevalence as 8.7. GJH is a clinical syndrome that is characterised with the fact that the joints have a range of motion above normal levels without a correlation with any systemic rheumatismal disease. The specific definition of GJH was shown by Kirk et al. in $1967{ }^{2}$

\section{REFERENCES:}

[1] Larsson LG, Baum J, Mudholkar GS. Hypermobility: Features and differential incidence between the sexes. Arthritis Rheum 1987; 30: 1426-30.

[2] Kirk JA, Ansell BM, Bywaters EG. The hypermobility syndrome. Musculoskeletal complaints associated with generalized joint hypermobility. Ann Rheum Dis 1967; 26: 419.

Disclosure of Interest: None declared DOI: 10.1136/annrheumdis-2018-eular.1511

\section{AB1114 SYSTEMIC JUVENILE IDIOPATHIC ARTHRITIS: A SINGLE CENTRE EXPERIENCE}

K. Barut, G. Tarcın, G. Tahaoglu, S. Sahin, A. Adrovic, O. Kasapcopur. Pediatric Rheumatology, Istanbul University, Cerrahpasa Medical School, Istanbul, Turkey

Background: Juvenile idiopathic arthritis (JIA) is the most common chronic rheumatic disease in childhood, divided into several subgroups. The sJIA could be presented by monocyclic, polycyclic or persistent polyarticular clinical course Macrophage activation syndrome (MAS) represents the most devastating complication that could appear during the disease course. Studies on follow up, treatment response and disease complications of the sJIA patients are spare and rare. Objectives: To evaluate demographic and clinical characteristics and to explore the long-term treatment response and disease complications in a large cohort of sJIA patients from the single centre.

Methods: Demographic and clinical features of the SJIA patients were reached from the patients's archives. The frequency of disease flares, treatment response and side effects were recorded for each patient.

Results: A total of 168 sJIA patients were included in the study: 87 (51.8) female, 81 (48.2) male. The clinical features are shown in table 1. Fifty-three (31.5 patients had monocyclic while 23 (13.7) patients had polycyclic clinical course (mean recurrency of attacks $2.5 \pm 2$ (IQR:1-4)): in 38(. ${ }^{42}$ Poliarticular course was present in 92 (54.8) patients. Initially diagnosis of patients were: infection in 86 (51.1), sJIA in 34 (20.4), acute rheumatic fever in 19 (11.3), urticaria in 10 (5.9), Kawasaki disease in 4 (2.4) and juvenile systemic lupus erythematosus in 2 patients.

The most common disease complications were: MAS in 20 (11.9), growth retardation in 19 (11.3) and vertebral fracture due to osteoporosis in 3 (1.9) patients. Gas trointestinal symptoms secondary to methotrexate intolerance that led to cessation of treatment were present in 9 (7.1) patients. Among 5 (2.9) patients that developed tuberculosis, 4 (2.3) were under etanercept treatment.

All of the patients were treated with corticosteroids: a doses of $2 \mathrm{mg} / \mathrm{kg} / \mathrm{day}$ in 118 (70.2) patients and pulse steroids in 50 (29.8) patients with severe clinical presentation. The methotrexate was used in 126 (75), leflunomide in 5 (3), cyclosporine A in 29 (17.3), intravenous immunoglobulin in 19 (11.3), anakinra in 27 (16.1), canakinumab in 27 (16.1), tocilizumab in 18 (10.7), etanercept in 50 (29.8) and adalimumab in 7 (4.2) patients. The median time to remission after the initial treatment with corticosteroids was 4 (IQR:2-4) months. The remission off medications was achieved in 82 (48.8) while remission on medications was achieved in 83 (49.4) of patients.

Table: Demographic, clinical features of SJIA

\begin{tabular}{lc}
\hline Female/male & $87(51.8) / 81(48.2)$ \\
\hline Mean age at disease onset & $76.7 \pm 54.5$ months (IQR: 28-118) \\
Mean age at diagnosis & $79,7 \pm 54.5$ months (IQR: $33-121)$ \\
Clinical features, $\mathbf{n}(\%)$ & \\
$-\cdot$ Typical fever & $160(95.2)$ \\
$-\cdot$ Typical rash & $99(59)$ \\
$-\cdot$.ymphadenopathy & $45(26.8)$ \\
$-\cdot$ Hepatosplenomegaly & $70(41.7)$ \\
$-\cdot$ Arthritis/arthralgia & $143(85.1), 25(14.9)$
\end{tabular}

Conclusions: Systemic JIA is a subtype of JIA characterised by significant morbidity and mortality rate with macrophage activation syndrome being the most severe disease complication. Corticosteroids represent the main treatment modality. Biological agents should be considered in the steroid-resistant patients.
The clinical remission could be achieved and chronic arthritis sequelae could be prevented in a majority of patients with biological agents.

\section{REFERENCE:}

[1] Barut K, Adrovic A, Sahin S, Kasapcopur O. Juvenile Idiopathic Arthritis Balkan medical journal. 2017;34:90-101

Disclosure of Interest: None declared

DOI: 10.1136/annrheumdis-2018-eular.3594

\section{AB1115 SYSTEMIC LUPUS ERYTHEMATOSUS IN PAEDIATRIC POPULATION- A SINGLE CENTRE STUDY FROM INDIA}

\section{P.P. Giri ${ }^{1}$, P. Pal ${ }^{2} .{ }^{1}$ pediatrics; ${ }^{2}$ ich, kolkata, India}

Background: systemic lupus erythematosus is an autoimmune disease that can be manifest in paediatric polpulation in various ways. It is characterised by widespread inflammation of the blood vessels and connective tissues with positive autoantibodies. Though it is a chronic disease it can be fatal at times.

Objectives: 1 . To study the diversity in clinical and laboratory profile in paediatric systemic lupus erythematosus patients at a tertiary care centre in Kolkata.

2. To identify the poor prognostic factors at the time of admission to the hospital.

3. To quantify the drug related adverse effects in follow up.

Methods: Both old known cases and newly diagnosed cases of paediatric SLE who presented to our rheumatology follow up clinic over last 18 months were retrospectively reviewed for their clinical and immunological presentation.SLICC diagnostic criteria has been applied to define a positive case.

Results: A total number of 64 patients were evaluated, among which 54 were girls and 10 were boys with a sex ratio of $5.4: 1$ favouring girls. Mean age on presentation was 9.9 years with a range of 2.5 to 16 years. Among the clinical presentation fever (72\%) was the most common symptom, followed by skin manifestation $(68.8 \%)$, musculoskeletal involvement $(53.1 \%)$, haematological involvement (37.5\%). Renal involvement was seen in 35.9\%, among which $59.1 \%$ had stage IV lupus nephritis, and central nervous system involvement was observed in 10.9\%. Among immunological profile, ANA was positive in $95.3 \%$, anti-double-stranded DNA was positive in

$92.1 \%$ and low complement levels were seen in $92.1 \%$. Antiphospholipid antibody was seen in 7

patients $(n=21)$ and anti-Smith antibody in $3(n=4)$. All the patients required therapy with steroids and hydroxychloroquine. Steroid sparing agents like azathioprine $(54.7 \%)$, cyclophosphamide $(28.1 \%)$, mycophenolate mofetil $(23.4 \%)$ methotrexate (18.7\%), and rituximab (10.9\%) were also used

Conclusions: Paediatric SLE has got a varied presentation, and a high index of suspicion is needed for early diagnosis and timely management with multiple drugs of this dreadful disease

Disclosure of Interest: None declared

DOI: 10.1136/annrheumdis-2018-eular.3921

\section{AB1116 MACROPHAGE ACTIVATION SYNDROME: AN EXPERIENCE FROM A TERTIARY PAEDIATRICCARE SETTING IN EASTERN INDIA}

\section{P.P. Giri, P. PAL, J. bhatia. pediatrics, institute of child health, Kolkata, India}

Background: Macrophage activation syndrome (MAS) is a rare but potentially fatal complication of systemic inflammatory disorders occurring most commonly in Systemic arthritis(SJIA) but also being increasingly reported in SLE, Kawasak disease and Periodic Fever Syndromes. We present a series of 29 cases of MAS encountered in the last 9 years in a tertiary paediatric care setting in eastern India. Objectives: The objective of this study is to evaluate the clinical features, laboratory findings and outcome in MAS; to assess the treatment response to different therapies and to identify the poor prognostic factors.

Methods: It is a prospective analysis of data of patients diagnosed as having MAS, between July 2008 and April 2017, admitted in the Department of Paediatrics at Institute Of Child Health, Kolkata.

All patients with Haemophagocytic Lymphohistiocytosis $(\mathrm{HLH})$ secondary to auto immune or inflammatory connective tissue diseases were included whereas HLH secondary to infections were excluded. Diagnosis of $\mathrm{HLH}$ was based on the HLH 2004 criteria. MAS diagnostic criteria for SJIA was laid down in 2014. , Post 2014 we used those criteria in SJIA patients.

The data noted were the clinical and laboratory features, treatment details, the response to therapy and outcome.

Results: Twenty nine $(n=29)$ patients were found to have MAS with the primary illness being SJIA in 24 (83\%), SLE in 4 (14\%) and Kawasaki Disease in 1 (3\%). The mean age at presentation was 5 years 3 months. The male female ratio was $1.2: 1$. Neurological, cardiac, renal and pulmonary involvement was seen in 21 (72\%), $14(48 \%), 6(20 \%)$ and $5(17 \%)$ patients respectively. Pulse methyl 
prednisolone $(30 \mathrm{mg} / \mathrm{kg})$ for 3 days was given in 27 patients. Two patients received hydrocortisone in SJIA MAS secondary to infections (chickenpox, Hepatitis A). In patients unresponsive to steroids IVIG and/or cyclosporine was used. $19(65 \%)$ patients survived whereas $10(35 \%)$ died. Of the 10 who succumbed, the $\mathrm{HLH} 2004$ protocol (including etoposide) was used in 2 who were refractory to pulse methylprednisolone +cyclosporine +IV Ig, but without any success. 2 patients on Tocilizumab had silent MAS.

Ferritin $>50000 \mathrm{ng} / \mathrm{ml}$ was seen in 11 patients of which 8 died. Chi square test of significance was done and $p$ value $(0.001)$ was significant for mortality in patients with ferritin $>50000 \mathrm{ng} / \mathrm{ml}$, with a positive correlation (0.613).

Patients with cardiovascular involvement especially pericardial effusion in SJIA was observed to have higher mortality but no statistical correlation could be made Conclusions: MAS is a fatal complication with a high mortality rate of $35 \%$ in our series. Ferritin levels $>50,000 \mathrm{ng} / \mathrm{ml}$ was associated with high mortality. Early and aggressive intervention with optimal intensive care support maybe life saving

Disclosure of Interest: None declared

DOI: 10.1136/annrheumdis-2018-eular.3951

\section{AB1117 ISOLATED CERVICAL ARTHRITIS AS THE SOLE MANIFESTATION OF FAMILIAL MEDITERRANEAN FEVER: A CASE REPORT}

R. Dagher ${ }^{1}$, M. Samarani ${ }^{1}$, A. Chelala ${ }^{2}$, M.C. Fadous Khalife ${ }^{1} .{ }^{1}$ pediatrics;

${ }^{2}$ radiology, Notre Dame de Secours University Hospital, Byblos, Lebanon

Background: Familial Mediterranean Fever (FMF) is an autosomal recessive disease affecting mainly eastern Mediterranean populations. Fever and Abdomina pain are the 2 most prevalent features. The most common arthritic manifestation of FMF is acute self-limiting monoarthritis. $5 \%$ of FMF patients develop chronic erosive arthritis. FMF mutation M694V has been associated to an increased risk of spondylarthropathy.

Objectives: We report the case of a child with cervical spine inflammation as the sole presentation of FMF.

Methods: A boy born to non-consanguineous parents presented at the age of 4 with complete blockage of his neck. He was described to have experienced progressive neck stiffness since the age of 3 years. His history is notable for intermittent limp at the age of 1 with complete spontaneous remission, and possible recurrent fever in the first 2 years of life. Family history is negative.

His physical exam revealed a painful and completely blocked neck in all movements, and stubby fingers. He had failure to thrive and a big belly without hepatos plenomegaly. Cognitive development was normal.

Laboratory tests revealed increased inflammatory markers. Other biological tests were insignificant. ANA, RF, anti-CCP and HLA B27 were negative. Lysosomal enzyme activities were normal ruling out muccopolysacharidosis, mucolipidoses and multiple sulfatase deficiencies. Work-up for failure to thrive was noncontributory. Ophtalmic screening showed no abnormalities.

Cervical spine plain radiographs were normal. Cervical MRI showed global contrast enhancement of cervical vertebrae and joints with blurring of the osseous contours and synovial inflammation; bone oedema was noted and involved some posterior arcs, spinous processes and pedicules. Sacro-iliac MRI was normal. The child was treated with oral steroids along with methotrexate and etanercept secondarily due to steroid dependance. Inflammatory markers normalised and clinical improvement was noted as the range of motion of neck increased and pain subsided. Repeated MRI after 6 months showed an almost normal image.

Results: Given this atypical isolated inflammation of the cervical spine, genetic testing for FMF was conducted. We identified 2 typical mutations (M694V and M694I) confirming the diagnosis of FMF. Colchicine treatment was started.

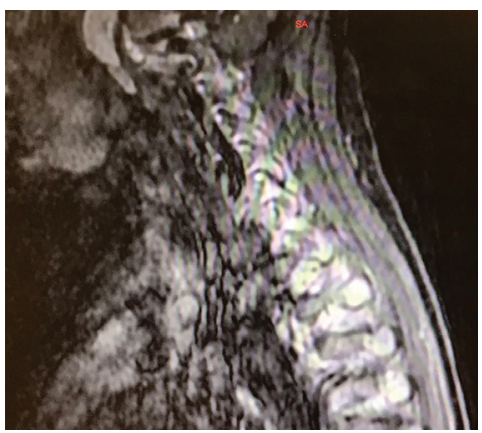

Abstract AB1117 - Figure

Conclusions: To the best of our knowledge, this is the first report of FMF masquerading as neck arthritis. Early spondylarthropathy is a possibility, but this unusual neck inflammation might be an isolated arthritis associated to FMF. Based on this clinical presentation, in the setting of atypical arthritis, diagnosis of FMF is to be raised in at-risk ethnicities, even in the absence of familial history and common clinical signs.

\section{REFERENCES}

[1] Sönmez HE,Batu ED,Demir S,Bilginer Y,Özen S. Comparison of patients with familial Mediterranean fever accompanied with sacroiliitis and patients with juvenile spondyloarthropathy. Clinical and Experimental Rheumatology. 2017 Nov-Dec;35 Suppl 108(6):124-127

[2] Younes M,Kahn MF,Meyer O. Hip involvement in patients with familial Mediterranean fever. A review of ten cases. Joint Bone Spine. 2002 Dec;69(6):560-5.

[3] Güncan S, Bilge NŞY, Cansu DÜ, Kaşifoğlu T, Korkmaz C. The role of MEFV mutations in the concurrent disorders observed in patients with familial Mediterranean fever. European Journal of Rheumatology. 2016;3 (3):118-121.

Disclosure of Interest: None declared

DOI: 10.1136/annrheumdis-2018-eular.2825

\section{AB1118 PROCALCITONIN DIFFERENTIATES INFECTION FROM ACTIVE DISEASE IN PATIENTS WITH JUVENILE IDIOPATHIC ARTHRITIS (JIA)}

R. Trachtman ${ }^{1}$, E.T. Murray ${ }^{2}$, N. Pan ${ }^{1}$, S.S. Toussi ${ }^{1}$, M.E. Nellis ${ }^{3}$, J. Szymonifka ${ }^{2}$ S.F. Taber ${ }^{1}$, A.B. Adams ${ }^{1}$, K.B. Onel ${ }^{1}$, L.A. Mand ${ }^{1} .{ }^{1}$ Hospital for Special Surgery/ Weill Cornell Medicine; ${ }^{2}$ Hospital for Special Surgery, ${ }^{3}$ Weill Cornell Medicine, New York, USA

Background: Patients with JIA often present with signs and symptoms sugges tive of infection. However, differentiation of infectious from non-infectious presentation in routine clinical care is challenging. Procalcitonin (PCT) is a serum biomarker elevated in the setting of bacterial infection, but whether it can reliably differentiate infection from disease flare in patients with JIA is unknown. ${ }^{1}$

Objectives: To test the hypothesis that PCT levels will differ between active JIA quiescent JIA, bacteremic patients and healthy controls.

Abstract AB1118 - Table 1. Patient Characteristics

\begin{tabular}{|c|c|c|c|c|}
\hline & $\begin{array}{c}\text { Active Untreated } \\
\text { JIA } \\
(n=12)\end{array}$ & $\begin{array}{c}\text { Quiescent } \\
\text { JIA } \\
(n=15)\end{array}$ & $\begin{array}{c}\text { Healthy } \\
\text { Controls } \\
(n=16)\end{array}$ & $\begin{array}{c}\text { Bacteremic } \\
\text { Patients } \\
(n=5)\end{array}$ \\
\hline $\begin{array}{l}\text { Age, years } \\
\text { (median, IQ } \\
\text { range) }\end{array}$ & $\begin{array}{c}9.0 \\
{[2.4-12.8]}\end{array}$ & $\begin{array}{c}14.5 \\
{[9.9-17.4]}\end{array}$ & $\begin{array}{c}14.4 \\
{[13.9-15.5]}\end{array}$ & $\begin{array}{c}1.1 \\
{[0.8-1.8]}\end{array}$ \\
\hline $\begin{array}{l}\text { Male Gender } \\
\text { Race }\end{array}$ & $5(41.7 \%)$ & $3(20.0 \%)$ & $6(37.5 \%)$ & $3(60.0 \%)$ \\
\hline $\begin{array}{l}\text { Caucasian/ } \\
\text { White }\end{array}$ & 7 (58.3\%) & 14 (93.3\%) & 12 (75.0\%) & $2(50.0 \%)$ \\
\hline AA/Black & 1 (8.3\%) & $0(0.0 \%)$ & $3(18.8 \%)$ & $1(25.0 \%)$ \\
\hline Asian & $3(25.0 \%)$ & $1(6.7 \%)$ & $0(0.0 \%)$ & $1(25.0 \%)$ \\
\hline Other & $1(8.3 \%)$ & $0(0.0 \%)$ & $1(6.3 \%)$ & $0(0.0 \%)$ \\
\hline $\begin{array}{l}\text { Hispanic } \\
\text { Ethnicity }\end{array}$ & $2(16.7 \%)$ & 2 (13.3\%) & $1(6.3 \%)$ & $1(20.0 \%)$ \\
\hline $\begin{array}{l}\text { Private } \\
\text { Insurance }\end{array}$ & 7 (58.3\%) & 14 (93.3\%) & 14 (87.5\%) & $4(80.0 \%)$ \\
\hline
\end{tabular}

Abstract AB1118 - Table 2. Laboratory Data

\begin{tabular}{|c|c|c|c|c|c|}
\hline & $\begin{array}{c}\text { Active } \\
\text { Untreated JIA } \\
(n=12)\end{array}$ & $\begin{array}{c}\text { Quiescent } \\
\text { JIA } \\
(n=15)\end{array}$ & $\begin{array}{l}\text { Healthy } \\
\text { controls } \\
(n=16)\end{array}$ & $\begin{array}{c}\text { Bacteremic } \\
\text { patients } \\
(n=5)\end{array}$ & $\begin{array}{c}\mathrm{p}- \\
\text { value }\end{array}$ \\
\hline $\begin{array}{l}\text { WBC (mean, } \\
\text { SD) }\end{array}$ & $8.9 \pm 4.4$ & $7.7 \pm 1.6$ & $6.7 \pm 1.7$ & $13.1 \pm 12.1$ & 0.06 \\
\hline ESR & 6.0 & 8.0 & 8.0 & 43.0 & 0.18 \\
\hline $\begin{array}{l}\text { Normal }<10 \\
\text { (median, IQR) }\end{array}$ & {$[4.0-46.0]$} & {$[5.0-10.0]$} & {$[5.0-10.0]$} & [20.0-66.0] & \\
\hline CRP & 0.27 & 0.31 & 0.44 & 16.63 & 0.067 \\
\hline $\begin{array}{l}\text { Normal<1 } \\
\text { (median, IQR) }\end{array}$ & [0.12-6.48] & {$[0.16-2.65]$} & {$[0.12-1.85]$} & [7.76-25.68] & \\
\hline $\begin{array}{l}\text { PCT } \\
\text { (median, IQR) }\end{array}$ & $\begin{array}{c}0.00 \\
{[0.00-0.00]}\end{array}$ & $\begin{array}{c}0.00 \\
{[0.00-0.00]}\end{array}$ & $\begin{array}{c}0.00 \\
{[0.00-0.00]}\end{array}$ & $\begin{array}{c}5.78 \\
{[4.26-52.00]}\end{array}$ & $<0.001$ \\
\hline
\end{tabular}

Methods: From 10/16-4/17, consecutive children 6 months - 18 years with a) active untreated JIA b) quiescent JIA and c) healthy pre-surgical candidates were recruited from a musculoskeletal specialty hospital. JIA was defined according to ILAR criteria. Patients with active JIA despite treatment were excluded, to avoid 